\title{
On the stability of cracking in tapered DCB testpieces
}

\author{
Y. W. MAI, A. G. ATKINS and R. M. CADDELL \\ Department of Mechanical Engineering, 2046 East Engineering Building, University of Michigan, Ann Arbor, \\ Michigan 48104, U.S.A.
}

(Received June 10, 1974; in revised form February 14, 1975)

\begin{abstract}
The conventional tapered DCB specimen loaded at the apex is shown to exhibit less stability than parallel DCB testpieces cracking under stiff testing conditions. A modified test with loadings applied at the thick base instead of near the apex is suggested. Experiments agree with theory that this provides better cracking stability and easier control of the crack path, along with a wider range of crack velocities in one test.
\end{abstract}

\section{Nomenclature}

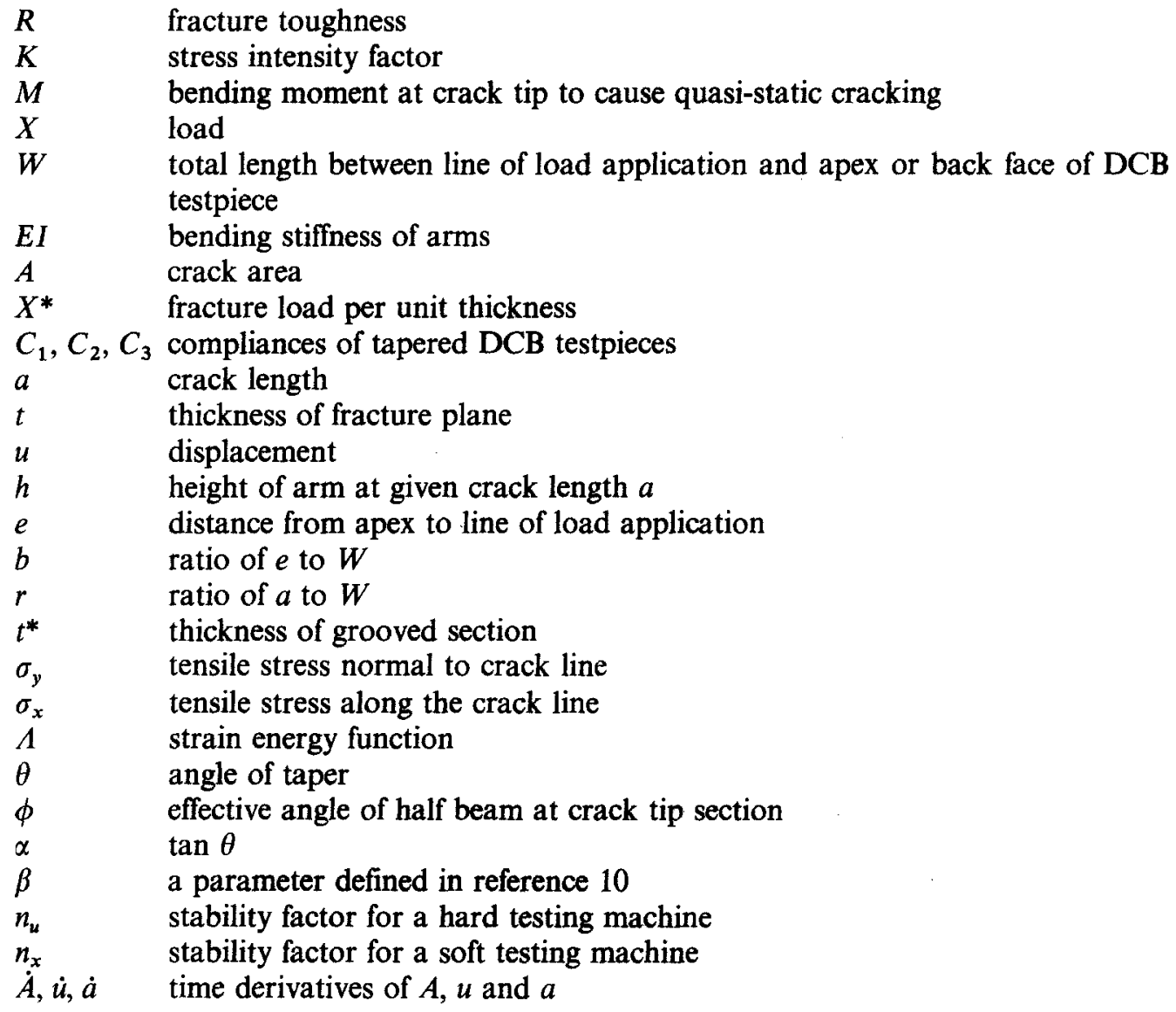

\section{Introduction}

Many workers have used the Double Cantilever Beam (DCB) testpiece with parallel arms for the determination of fracture toughness [1-8]. In these investigations, the crack was made to propagate in a controlled and stable manner so that a number of observations 
could be made on one sample. It may be shown [7] that the moment required at the crack tip for quasi-static cracking is

$$
M^{2}=R /\left[\frac{1}{E I t}+\frac{1}{t} \frac{\partial}{\partial a}(\phi / M)\right]
$$

with the meaning of the symbols as given in the nomenclature.

In addition, DCB specimens with arms that increase in height in the direction of crack propagation have been employed [9], particularly in fatigue studies and environmental cracking investigations. Such tapered specimens can possess "constant rate of change of compliance" characteristics for a certain range of crack length, so that cracking takes place at constant stress intensity factor and constant velocity under constant load.

Figure 1 shows a tapered semi-infinite DCB testpiece of thickness $(t)$ with a pair of self-equilibrating forces $(X)$, applied at a distance $(e)$ from the apex. Strawley and Gross [10] from boundary collocation methods give two expressions for the stress intensity factor, depending upon the range of $(a / W)$. For $a / W<0.7$,

$$
K t h^{\frac{1}{2}} / X=\beta(a / h+0.7)
$$

where $\beta$ is a parameter which varies with the slope of the taper $\alpha[=h /(a+e)]$.

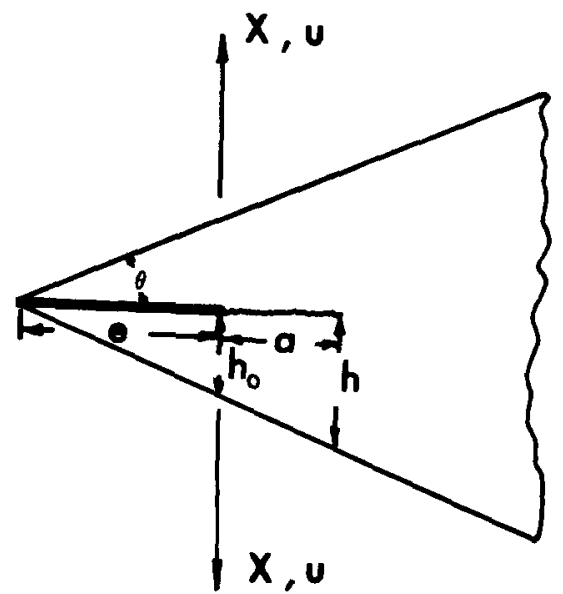

Figure 1. A semi-finite tapered DCB specimen.

For $a / W \geqq 0.7$

$$
K t W^{\frac{1}{2}} / X=[0.537+2.17(1+a / W) /(1-a / W)] /(1-a / W)^{\frac{1}{2}}
$$

To obtain the compliance of the testpiece for $a / W<0.7$, we note that [6]

$$
K^{2}=E R=\left(X^{2} / 2 t\right)(\mathrm{d} / \mathrm{d} a)[(u / X)] .
$$

Combining with (2), and performing the integration we have,

$$
\begin{aligned}
C_{1}= & (u / X)_{1}=\left(2 \beta^{2} / \alpha E T\right)\left\{\left(0.49+1.4 / \alpha+1 /(\alpha)^{2}\right) \ln (1+r / b)\right. \\
& \left.+\left(1.4 / \alpha+2 /(\alpha)^{2}\right)\left[b(r+b)^{-1}\right]-0.5 \alpha^{-2}\left[b(r+b)^{-1}\right]^{2}-1.4 / \alpha-3 /\left(2 \alpha^{2}\right)\right\}
\end{aligned}
$$

where $b=e / W$ and $r=a / W$. 


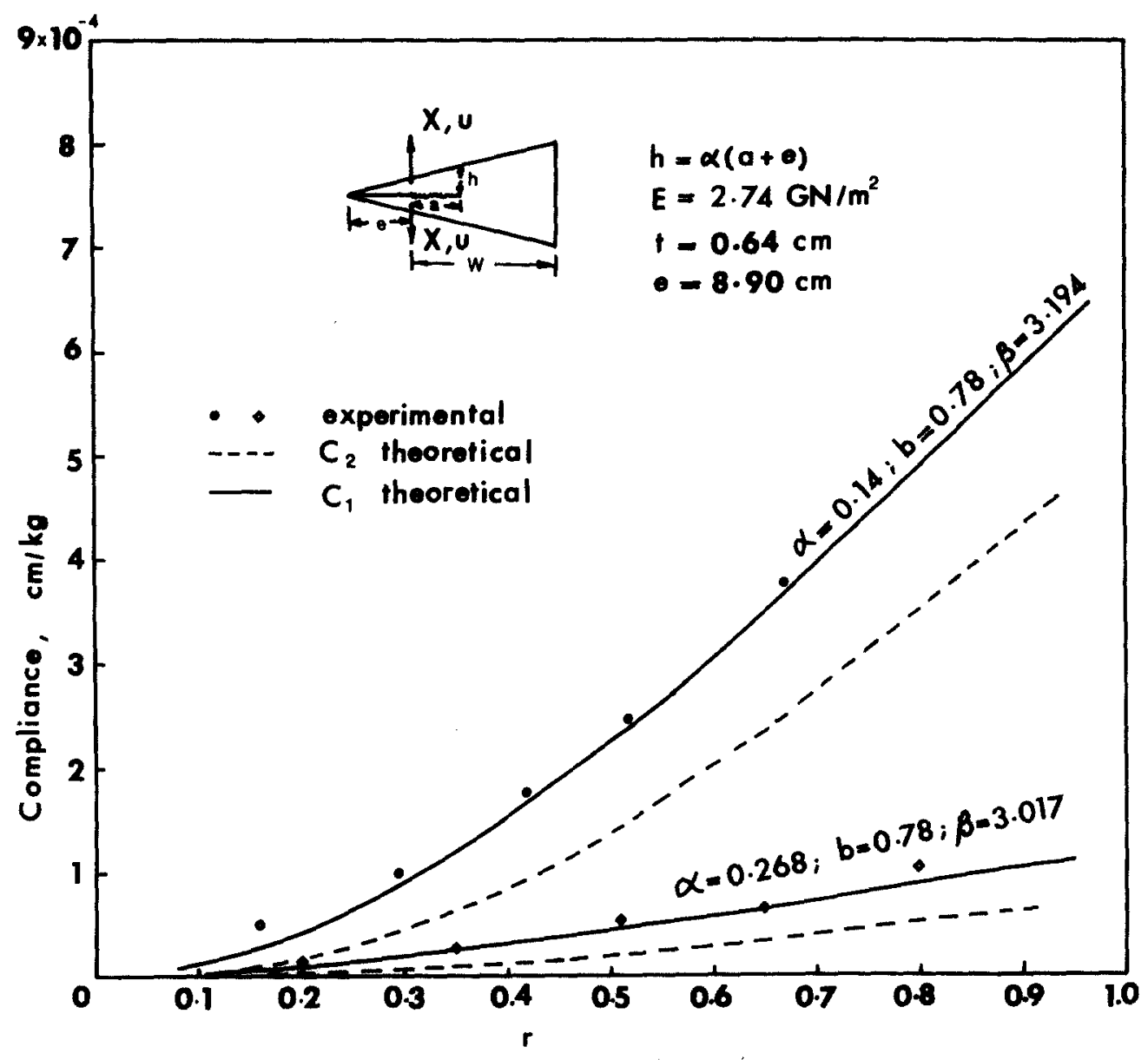

Figure 2. Comparison of theoretical and experimental compliances of tapered DCB specimens.

A more simply derived expression for the compliance of tapered DCB specimens was given by Gurney and Mai [8], as

$$
C_{2}=(u / X)_{2}=\left(24 / \alpha^{3} E t\right)\left[\ln (1+a / e)+2 e /(a+e)-0.5\left[e(a+e)^{-1}\right]^{2}-\frac{3}{2}\right]
$$

the derivation of which ignores crack end effects. As shown by the results of compliance experiments on PMMA testpieces in Fig. 2, Eqn. (6) is not as acceptable as (5).

The fracture load per unit thickness $\left(X^{*}\right)$ shown in Fig. 3 is given by (2) and (4) as

$$
\frac{X^{*}}{(E R W)^{\frac{1}{2}}}=\frac{\alpha^{\frac{1}{2}}}{\beta} \frac{(r+b)^{\frac{1}{2}}}{\left[0.7+\alpha^{-1}(1 /(1+b / r))\right]}
$$

Good agreement is achieved between experimental and theoretical values from (7) for $r<0.70$ for the two angles studied. However as the crack nears the thick base, (7) will be affected by hinge actions. Then, for $r>0.7, X^{*} /(E R W)^{\frac{1}{2}}$ tends to follow (3).

Figure 4 shows plots of $X^{*} /(E R W)^{\frac{*}{3}}$ against $r$ for $b^{-1}=3.0$ and $\alpha$ varying from 0.10 to 0.60 . It may be readily seen that for small $\alpha$ and over a reasonable length of $r$, the value of $X^{*} /(E R W)^{\frac{1}{2}}$ is essentially constant. For a material having a constant fracture toughness $(R)$ and rate independent modulus $(E)$, this means that the predicted fracture load per unit thickness of beam, $X^{*}$, is invariant. Such a design of 
testpiece is essential for stress corrosion cracking studies in which cracking mechanisms are investigated at constant $K$ or $R$. Note however that at sufficiently great $\alpha, X^{*} /(E R W)^{\frac{1}{2}}$ may just increase with $r$ without any appreciable constant range ( $c f$. the curve for $\alpha=0.6$ ).

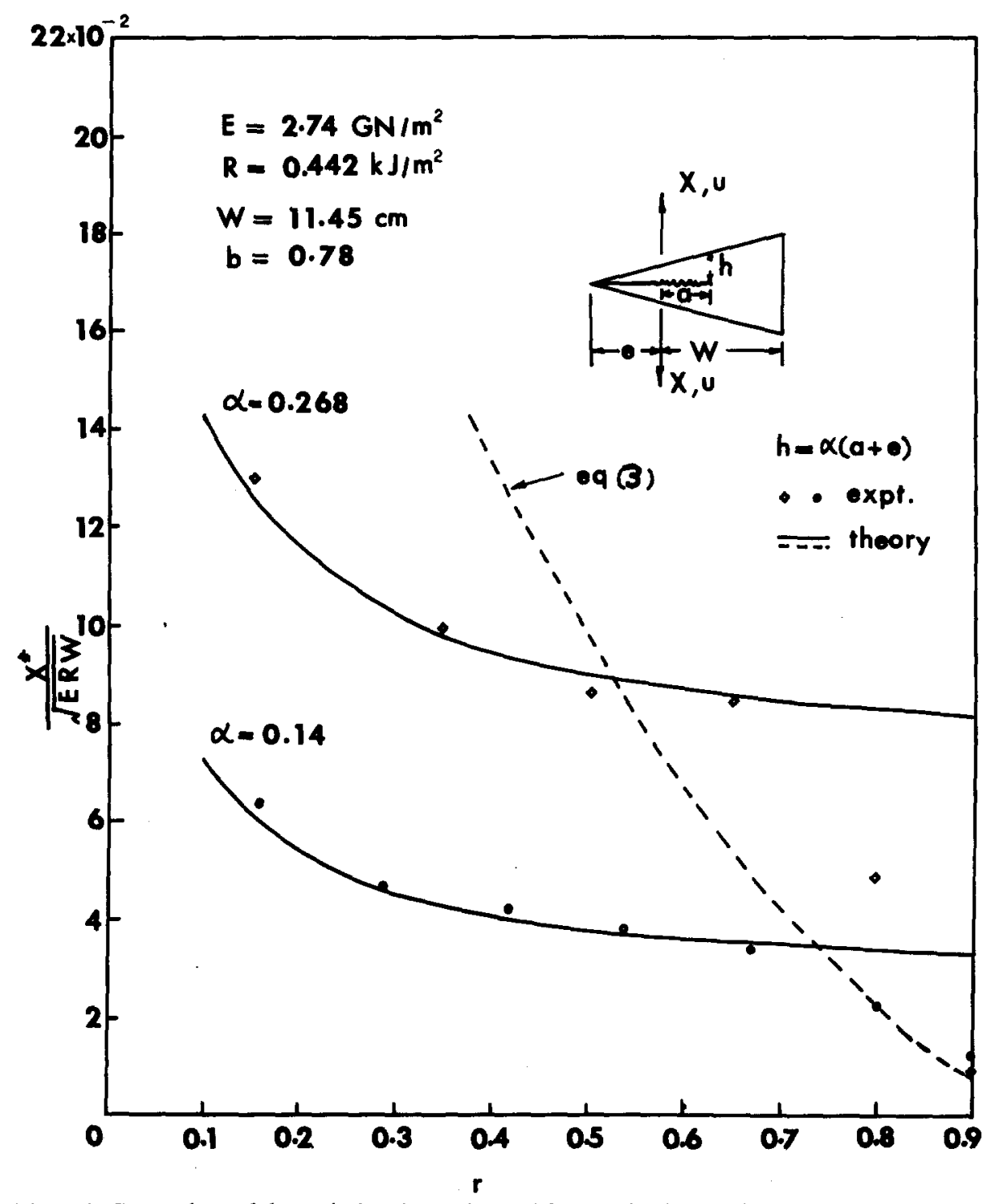

Figure 3. Comparison of theoretical and experimental fracture load per unit thickness of beam.

Thus the crack length over which the stress intensity factor is constant may be too short for experimental usefulness. Furthermore, experiments show that with improper design, conventionally tapered DCB testpieces may fail catastrophically under monotonic increasing load or displacement, and the crack may also curve to the sides of the testpiece e.g. $[9,11]$.

The present paper discusses some of the more significant results associated with cracking stability in conventionally tapered DCB specimens, based upon which a modified testing method is suggested where the loads are applied at the thick base of the tapered specimen rather than at the apex. This gives not only better crack stability but also relatively easy control of the path of the spreading crack together with a favourable reduction in crack velocity during testing. 


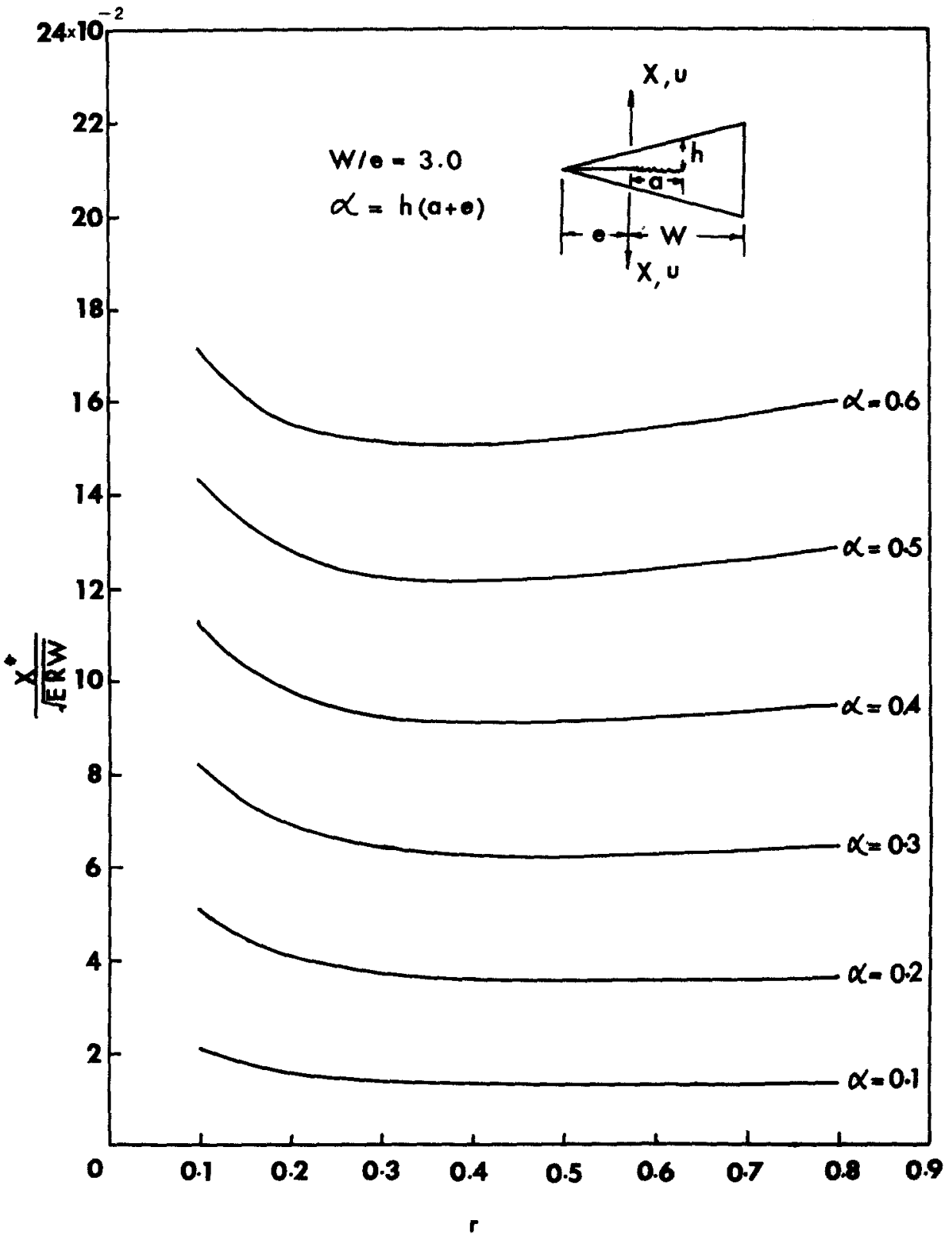

Figure 4. Variations of $X^{*} /(E R W)^{\frac{1}{2}}$ with $r$ for $W / e=3.0$.

\section{Stability of cracking}

Except in a few publications $[6-8,12]$, cracking stability has not received much attention in the study of Fracture Mechanics. However, this problem is particularly important in the sense that meaningful results on the work of fracture of materials can only be obtained with testpieces that produce stable cracking. Then, when crack propagation is controlled, we may be able to derive significant information on how $R$ varies with crack front speed $(\dot{a})$, in a given reference environment. Gurney and Hunt [6] and Clausing [12], independently formulated the criteria on fracture stability according to chosen constraints of the testing machines. As pointed out by Atkins and Caddell [13], the two approaches give essentially the same criteria for stability. Recently, Gurney and Mai [8] 
have made suggestions to promote stability in otherwise unstable materials. In general, we may express the stability criteria as follows:

(i) For a load-controlled machine, $\mathrm{d} X / X>0$,

$$
R^{-1}(\mathrm{~d} R / \mathrm{d} a)>\left(\mathrm{d}^{2} / \mathrm{d} a^{2}\right)[(u / X)] \div(\mathrm{d} / \mathrm{d} a)[(u / X)]
$$

(ii) For a displacement-controlled machine, $\mathrm{d} u / u>0$,

$$
\frac{1}{R} \frac{\mathrm{d} R}{\mathrm{~d} a}>\frac{\mathrm{d}^{2}}{\mathrm{~d} a^{2}}(u / X) \div \frac{\mathrm{d}}{\mathrm{d} a}\left(\frac{u}{X}\right)-\frac{2(\mathrm{~d} / \mathrm{d} a)(u / X)}{(u / X)}
$$

The right-hand sides of expression (8) are known as geometrical stability factors (g.s.f.) and may be simplified to $\left(n_{X} / a\right)$ and $\left(n_{u} / a\right)$ respectively where $n_{X}$ and $n_{u}$ are numerical numbers to be evaluated.

For a semi-infinite conventionally tapered DCB testpiece, the stability of cracking under $\mathrm{d} X / X>0$ is written as

$$
R^{-1}(\mathrm{~d} R / \mathrm{d} a)>\left(\mathrm{d}^{2} C_{1} / \mathrm{d} a^{2}\right) \div\left(\mathrm{d} C_{1} / \mathrm{d} a\right)>\left(n_{X} / a\right)
$$

where $C_{1}$ is given by (5). Numerically, $n_{X}$ is given by the following expression,

$$
\begin{aligned}
& n_{X}=-(r /(r+b))\left\{\left(0.49+1.4 / \alpha+1 /(\alpha)^{2}\right)-\left(1.4 / \alpha+2 / \alpha^{2}\right)[2 b /(r+b)]+3 b^{2} /\left[\alpha^{2}(r+b)^{2}\right]\right. \\
& \div\left[\left(0.49+1.4 / \alpha+1 /(\alpha)^{2}\right)-\left(1.4 / \alpha+2 /(\alpha)^{2}\right)[b /(r+b)]+b^{2} /\left[\alpha^{2}(r+b)^{2}\right]\right\}
\end{aligned}
$$

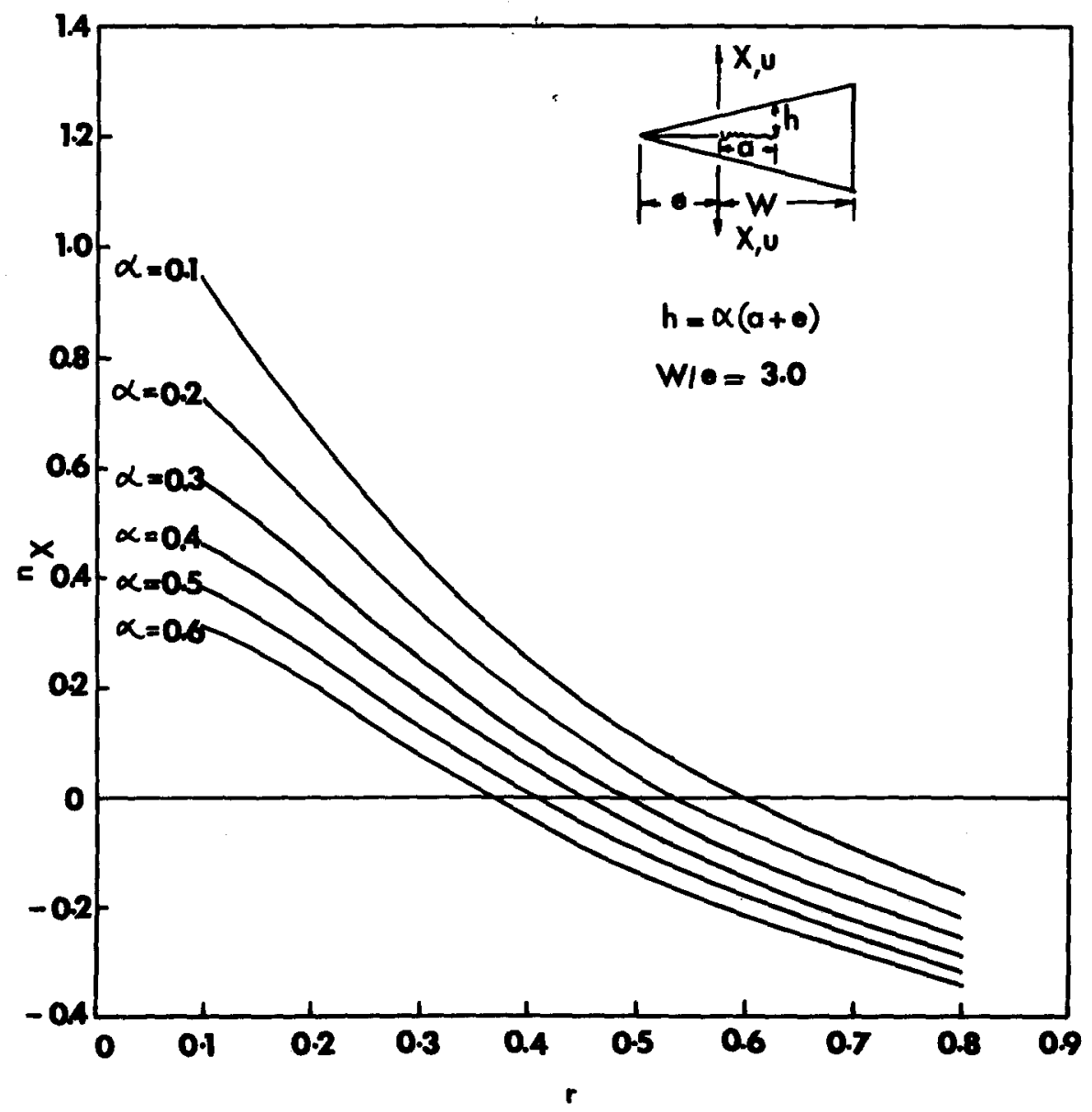

Figure 5. A plot of $n_{x}$ against $r$ for $W / e=3.0$; g.s.f. for a soft testing machine. 
For $b^{-1}=3.0$, the variations of $n_{X}$ with $r$ for different values of $\alpha$ are shown in Fig. 5 . It may be concluded from these curves that large taper angles increase the stability of cracking under "soft" testing conditions $(\mathrm{d} X / X>0)$, when compared with the corresponding case for beams with parallel arms when $n_{X}=2.0[6]$.

Reverting to the case when the experiment is performed under "stiff" testing conditions $(\mathrm{d} u / u>0)$, the second of Eqn. (8) gives the stability criterion as

where

$$
R^{-1}(\mathrm{~d} R / \mathrm{d} a)>\left(n_{u} / a\right)
$$

$$
\begin{aligned}
n_{u}=n_{X}- & {\left[2 r(r+b)^{-1}\right]\left\{\left(0.49+1.4 / \alpha+1 /(\alpha)^{2}\right)-\left[\left(1.4 / \alpha+2 / \alpha^{2}\right)\right]\left[\mathrm{b}(r+b)^{-1}\right]\right.} \\
+ & {\left.\left[b^{2} / \alpha^{2}(r+b)^{2}\right]\right\} \div C_{1}\left(\alpha E t / 2 \beta^{2}\right) }
\end{aligned}
$$

Figure 6 shows plots of $n_{u}$ against $r$ for varying $\alpha$ and for $b^{-1}=3.0$. These results suggest that stability of cracking in general has been reduced, and that parallel.DCB specimens are more stable [6].

The general conclusion thus reached is that in a stiff testing system, (e.g. a screw driven machine), tapers decrease stability for quasi-static cracking, and that increasing the angle worsens the instability. Experimental evidence in support of this argument

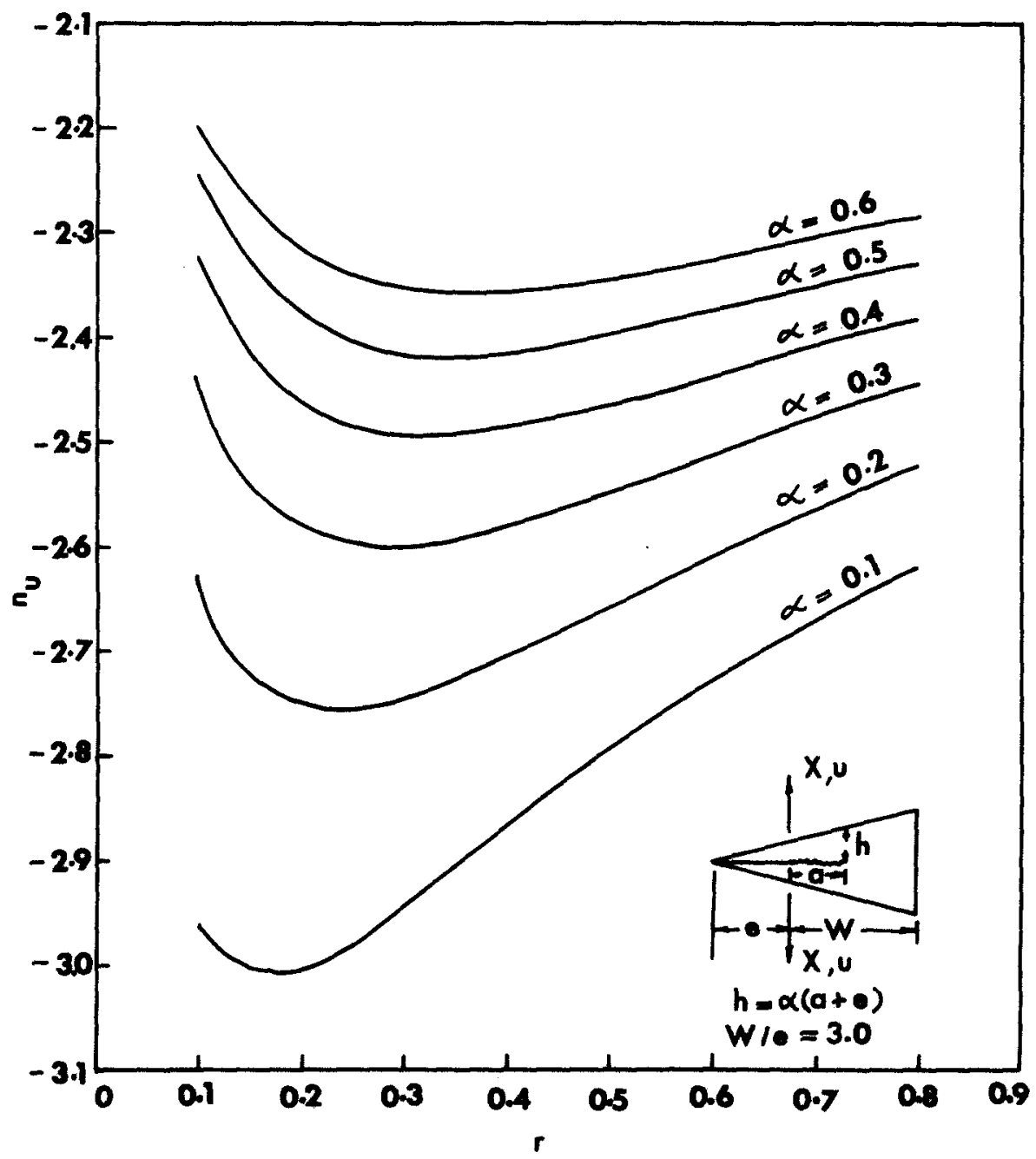

Figure 6. A plot of $n_{u}$ against $r$ for $W / e=3.0$; g.s.f. for a hard testing machine. 


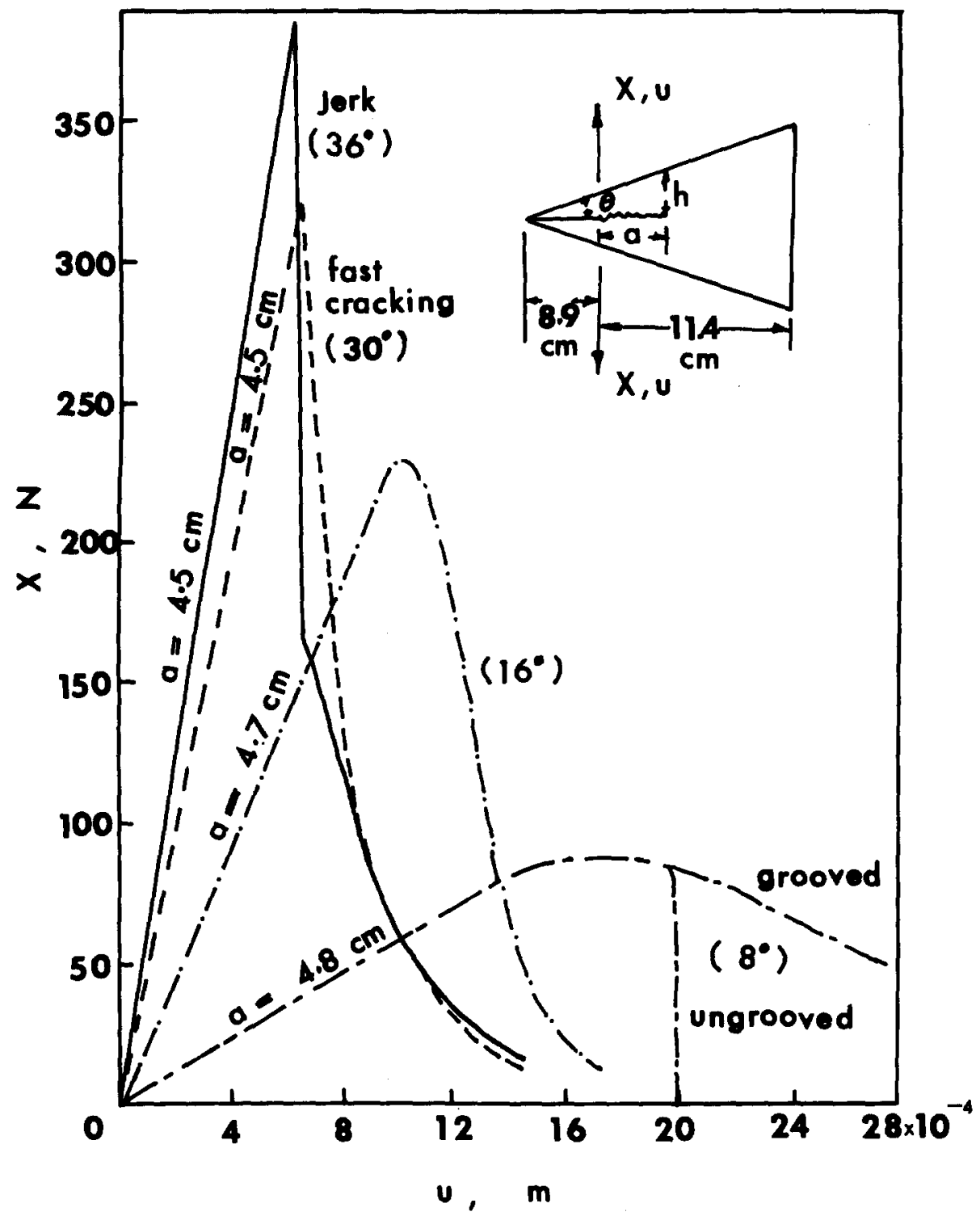

Figure 7. Effects of taper angles on the stability of cracking in perspex.

is presented in Fig. 7. Tests were performed on $0.64 \mathrm{~cm}$ thick PMMA DCB plates with varying angles of taper $(\theta)$ and dimensions as shown in the figure. The crosshead speed of the Instron was operated at $1.67 \times 10^{-5} \mathrm{~m} / \mathrm{s}$ and with ambient conditions of $52 \%$ R.H. and $293^{\circ} \mathrm{K}$. The starting crack to beam length ratio was kept approximately constant $(r=0.40)$ so that the relative stability or rate of cracking may be directly compared. It is seen that as $\theta$ increases, the rate of cracking is faster and becomes less controlled, until eventually at $\theta=36^{\circ}$, the initial crack spreading is completely unstable.

Although cracking of slender beams with small $\theta$ is comparatively stable, experiments show that the crack will veer out of the arms unless the testpiece is appropriately grooved (See Fig. 7, $\theta=8^{\circ}$ ). A straight crack may only be obtained in the full thickness by increasing the angle of the taper, but this is, of course at the expense of decreasing the stability of the spreading crack. Thus, it is apparent that design of the tapered DCB testpiece must be properly executed or else unexpected failure will occur. 


\section{Crack paths}

The predictions of crack paths under a given stress situation are very complicated [14-16]. It would now appear that crack paths should be those directions into which strain energy is released at the maximum rate $[6,17,18]$, which according to Gurney [6] is the direction of maximum rate of entropy production for a cracking process. Knauss [19] has demonstrated that the general segmented crack path which satisfies a maximum rate of strain energy dumping criterion coincides in the limit with curved maximum tensile stress trajectories. This explains the success of simple maximum stress criteria for crack path prediction based on elementary beam theory. For example, Cotterell [20] showed that for parallel DCB specimens an initial straight crack turns when $\sigma_{y}<\sigma_{x}$ where $\sigma_{x}$ and $\sigma_{y}$ are the beam tensile stresses along and normal to the crack line ${ }^{\star}$. In

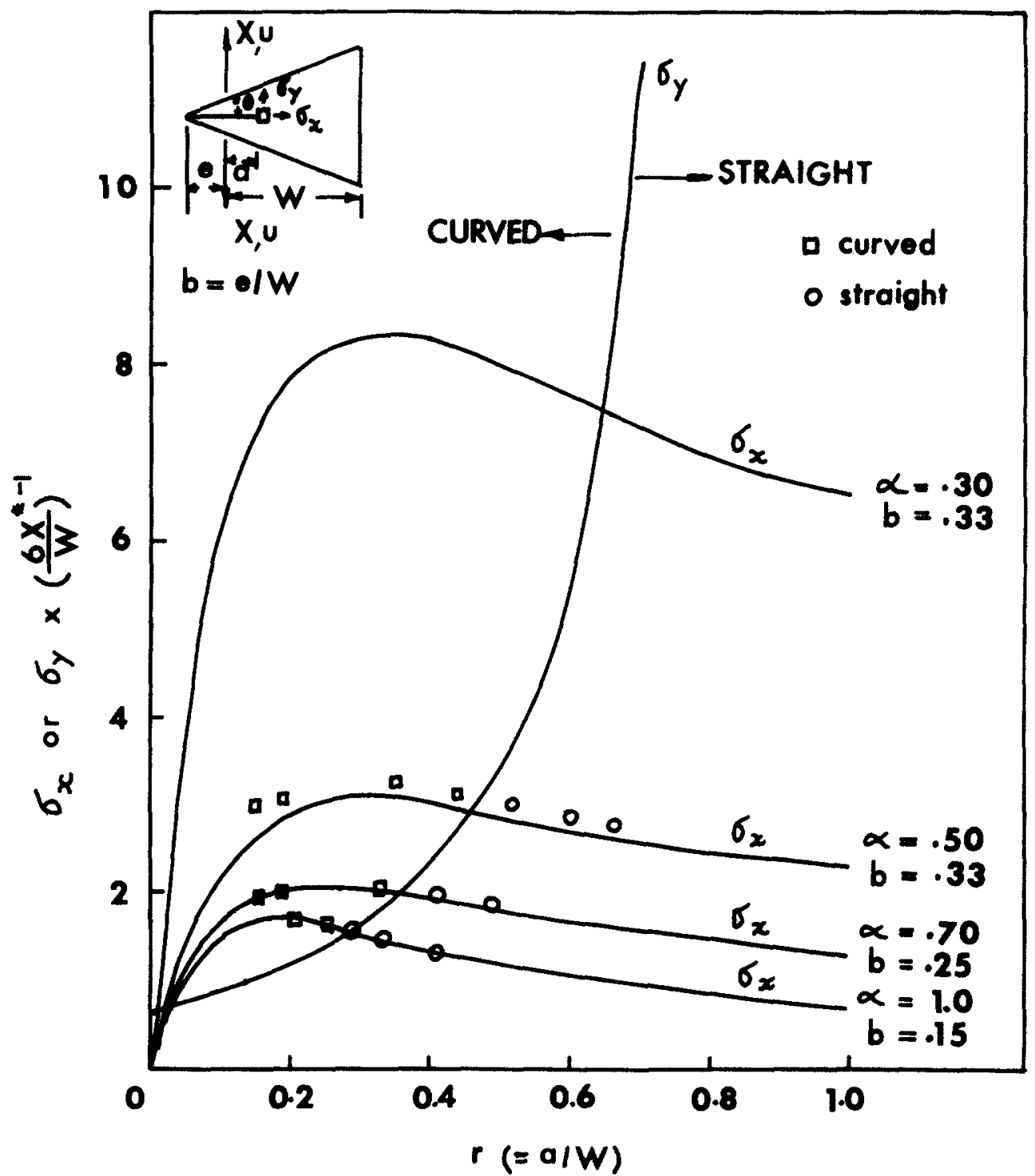

Figure 8. Determination of straight crack paths in conventional tapered DCB specimens.

* In Cotterell's published work [20], he omits the stress component due to the force transiation and there is a misprint in the power of the $\sigma_{y}$ expression. 
the present investigation, we have found that such a simple crack turning criterion also works well with the tapered DCB testpieces.

Consider the case when loadings are applied near the apex as shown in the inset of Fig. 8. We have, following Atkins and Caddell [11], for the tapered DCB specimen

$$
\begin{aligned}
& \sigma_{x}=\left(6 X^{*} / W\right) \cdot r /\left[\alpha^{2}(b+r)^{2}\right] \\
& \sigma_{y}=\left(2 X^{*} / W\right) \cdot\left[(2+r) /(1-r)^{2}\right]
\end{aligned}
$$

The shapes of the expressions for variation of $r$ at constant $\alpha$ are shown in Fig. 8. Straight crack paths are produced only when the $\sigma_{x}$ curves lie below $\sigma_{y}$. Equivalently, a minimum taper angle (varying with $r$ ) is required for a continuously straight propagating crack. We have from (11), for those angles,

$$
\alpha>\frac{(1-r)(3 r)^{\frac{1}{2}}}{(b+r)(2+r)^{\frac{1}{2}}}
$$

Experiments were performed where the starting crack to beam length ratios $(r)$ were varied from 0.15 to 0.65 while the semi-angles of the tapers were $25^{\circ}, 35^{\circ}$, and $45^{\circ}$. Experimental combinations of $(r, \alpha)$ occurring above the $\sigma_{y}$ line in Fig. 8 turned immediately with large deviations from the initial crack line. Straight cracks were only obtained when the combination fell below the $\sigma_{y}$ line as shown.

If grooves are cut in the mid-plane of the specimen to leave a net thickness $t^{*}$ along

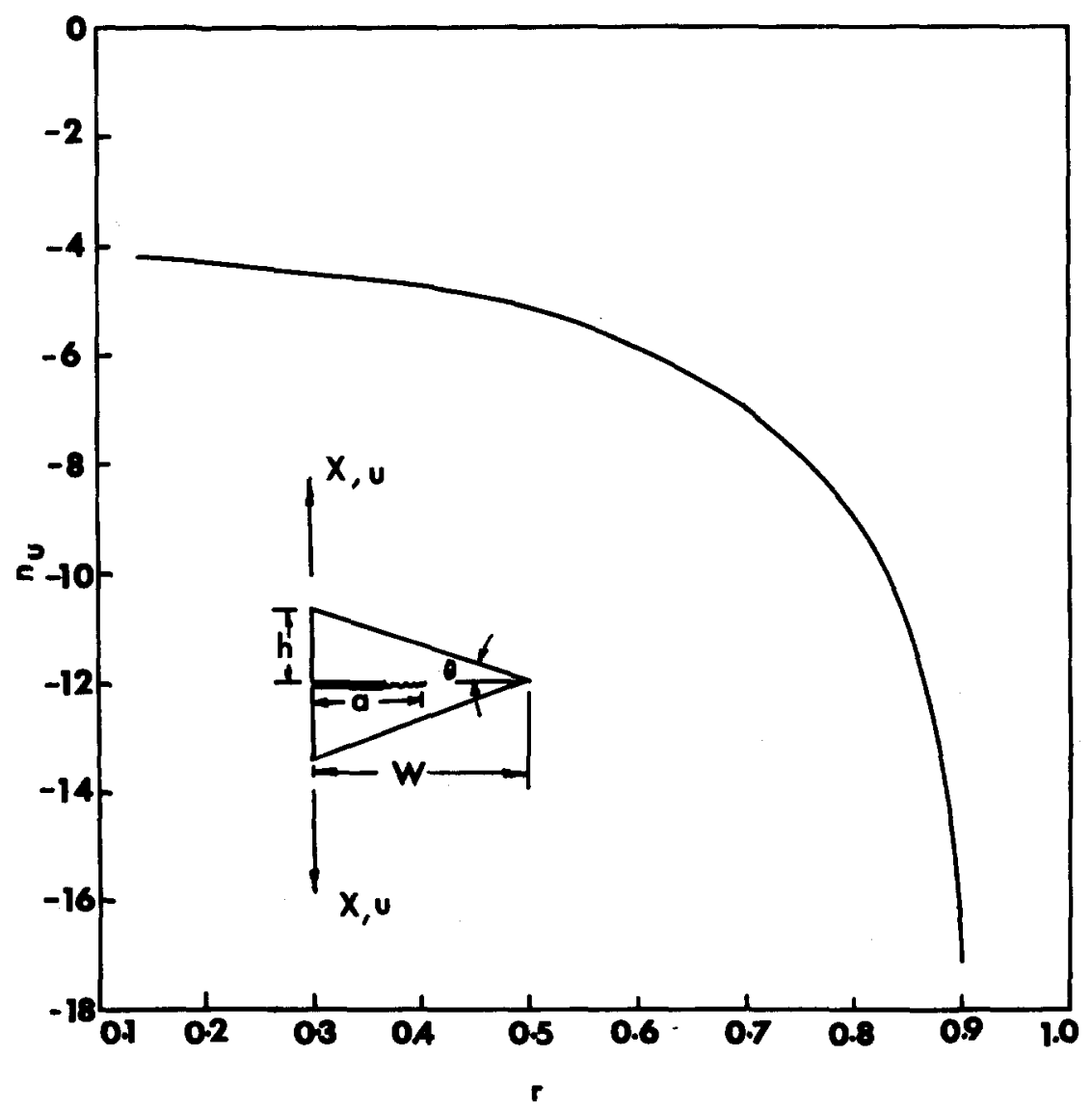

Figure 9. A plot of $n_{u}$ against $r$ for the modified test configuration. 
the groove, the expression for $\sigma_{y}$ in (11) becomes

$$
\sigma_{y}^{*}=\left(t / t^{*}\right) \sigma_{y}
$$

Cracks will climb out of the groove when

$$
\sigma_{x}>\sigma_{y}^{*}
$$

where $\sigma_{x}$ is still given by (11). Since $\sigma_{y}^{*}>\sigma_{y}$, straight cracks occur at smaller $\alpha$ than otherwise. However, numerous combinations of $(r, \alpha)$ still exist where cracks climb out of the grooves e.g. [9].

\section{A modified fracture toughness test}

Better control of crack path and stability of cracking in tapered DCB specimens may be obtained by applying the loads at the "thick base" instead of at the apex. Consider such a loading configuration as shown inset in Fig. 9. By neglecting crack end effects, the compliance relation is expressed as,

$$
C_{3}=(u / X)_{3}=\left(24 / \alpha^{3} E t\right)\left\{\ln \left[(1-r)^{-1}\right]-2 /(1-r)+[0.5(1-r)]^{-2}+\frac{3}{2}\right\}
$$

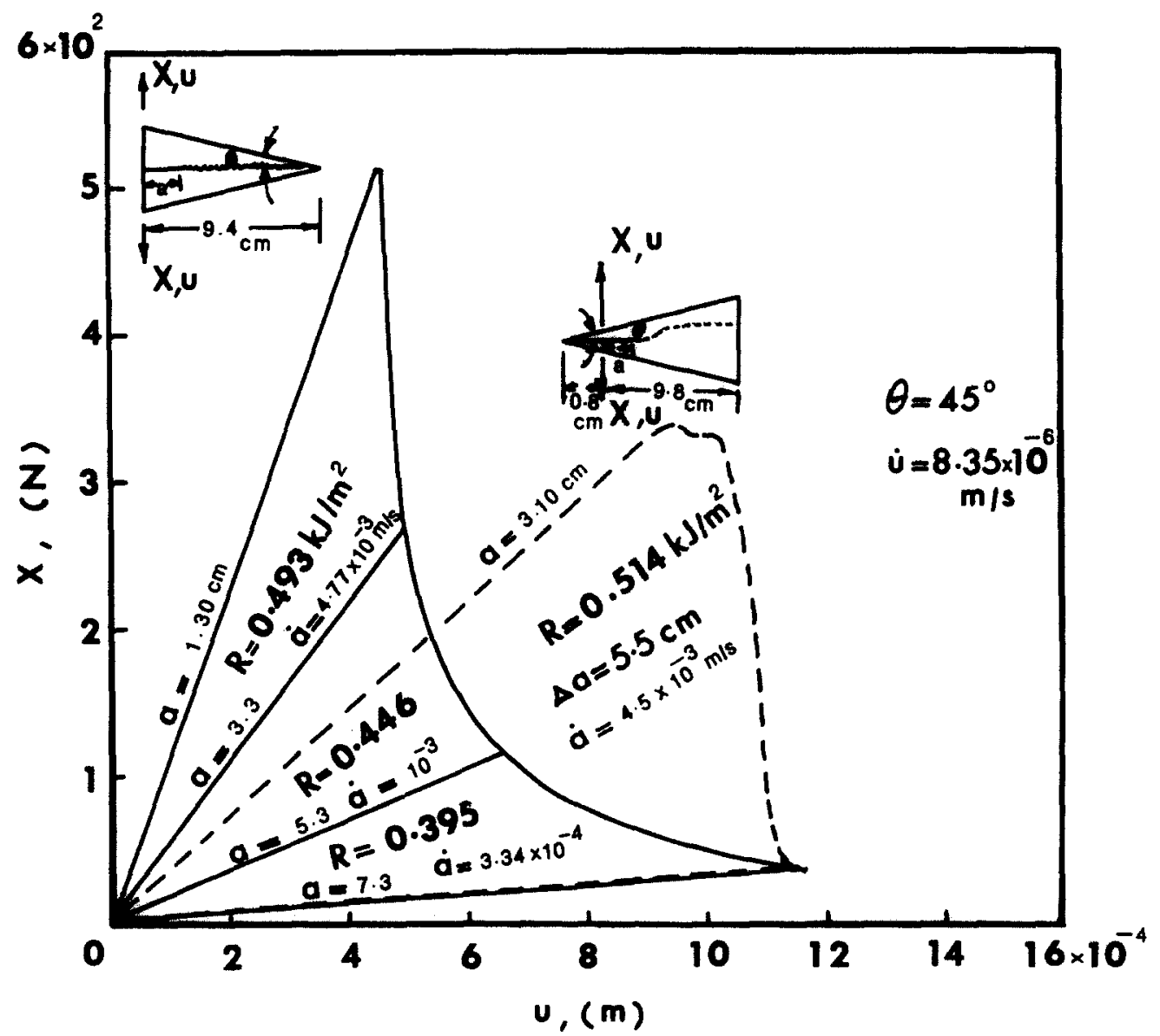

Figure 10. Rate of cracking in a modified and a conventional DCB tapered test specimen with $\theta=45^{\circ}$. 
which is analogous to $C_{2}$ for apex loading. We do not have a boundary collocation expression analogous to $C_{1}$.

The stability criterion governing the spreading crack in a hard testing machine may be worked out from the second of Eqn. (8). It may be shown that

$$
n_{u}=(2+r) /(1-r)-2[r /(1-r)]^{3} /\left[\ln [(1-r)]-2 /(1-r)+[0.5(1-r)]^{-2}+\frac{3}{2}\right]
$$

and is plotted in Fig. 9. Obviously, the stability of cracking is greatly improved as $r$ increases, and this provides a definite advantage over the conventional arrangement where loadings are applied close to the apex of the specimen. Figure 10 shows the cracking of $0.64 \mathrm{~cm}$ thick perspex sheet specimen with $\theta=45^{\circ}$ by shear forces applied at the thick base. Experimentally, very stable cracking is achieved with velocities ranging from $10^{-2} \mathrm{~m} / \mathrm{s}$ to $10^{-3} \mathrm{~m} / \mathrm{s}$ in a single test at a typical crosshead speed of $8.35 \times 10^{-6} \mathrm{~m} / \mathrm{s}$.

Moreover, the crack runs essentially straight and along the mid-plane of the testpiece (without grooving). For comparison, the test result performed on a similar specimen (i.e. $\theta=45^{\circ}$ ) with loading applied at the apex and under similar test conditions was also included in Fig. 10. It may be seen that the crack turned as indicated (see inset of figure) during spreading.

The ability of tapered DCB testpieces loaded at the thick base to produce straight cracks much more readily than similar specimens loaded at the apex, may be shown from simple beam theory. The respective stresses along and normal to the crack line are

$$
\begin{aligned}
& \sigma_{x}=\left(6 X^{*} / W\right) r /\left[\alpha^{2}(1-r)^{2}\right] \\
& \sigma_{y}=\left(2 X^{*} / W\right)(2+r) /\left[(1-r)^{2}\right]
\end{aligned}
$$

Following the same treatment in section 3, the minimum angle for a starting crack to propagate in a straight path is

$$
\alpha>[3 r /(2+r)]^{\frac{1}{2}}
$$

Figure 11a shows a plot of $\theta\left(=\tan ^{-1} \alpha\right)$ vs. $r$ for expression (17). It is noted that a straight crack will only propagate along the mid-plane for all $r$, when $\theta=45^{\circ}$. This is more obvious in Fig. $11 \mathrm{~b}$ as $\sigma_{y}$ is always greater than $\sigma_{x}$ at $\alpha=1.0$. Experiments were done on PMMA specimens with semi-angle $\theta=20^{\circ}, 25^{\circ}, 30^{\circ}, 35^{\circ}, 40^{\circ}$ and $45^{\circ}$, and with initial crack to beam length ratio $r=0.10$. The positions at which the crack turned were noted and these data points $(\theta, r)$ were superimposed on Fig. 1la. It is seen that the experimental and theoretical curves are in good agreement. This demonstrated that (16) and (17) provide an adequate criterion for crack turning.

Considerations of grooving apply as before which allow smaller values of $\alpha$ to be used.

\section{Crack velocities}

The crack velocities of quasi-static cracking may be obtained from the basic energy rate balance [8], i.e.

$$
X \mathrm{~d} u=\mathrm{d} A+R \mathrm{~d} A
$$

For linearly elastic systems, the change in strain energy $\mathrm{d} \Lambda$ is given by $\mathrm{d}(1 / 2 X u)$, whence

Thus

$$
X \mathrm{~d} u=2 R \mathrm{~d} A+u \mathrm{~d} X .
$$




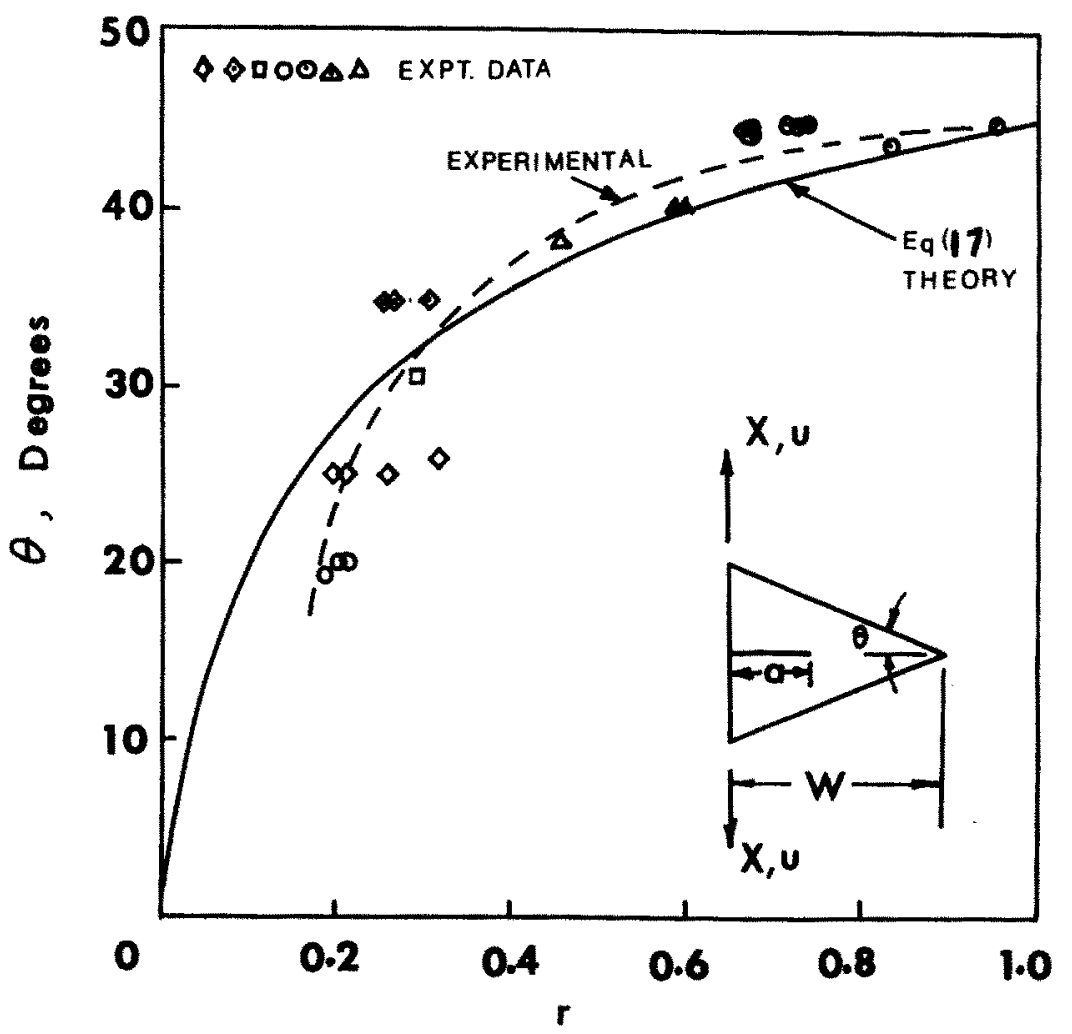

Figure 11a. Determination of straight crack paths in modified test configuration of tapered DCB specimens.

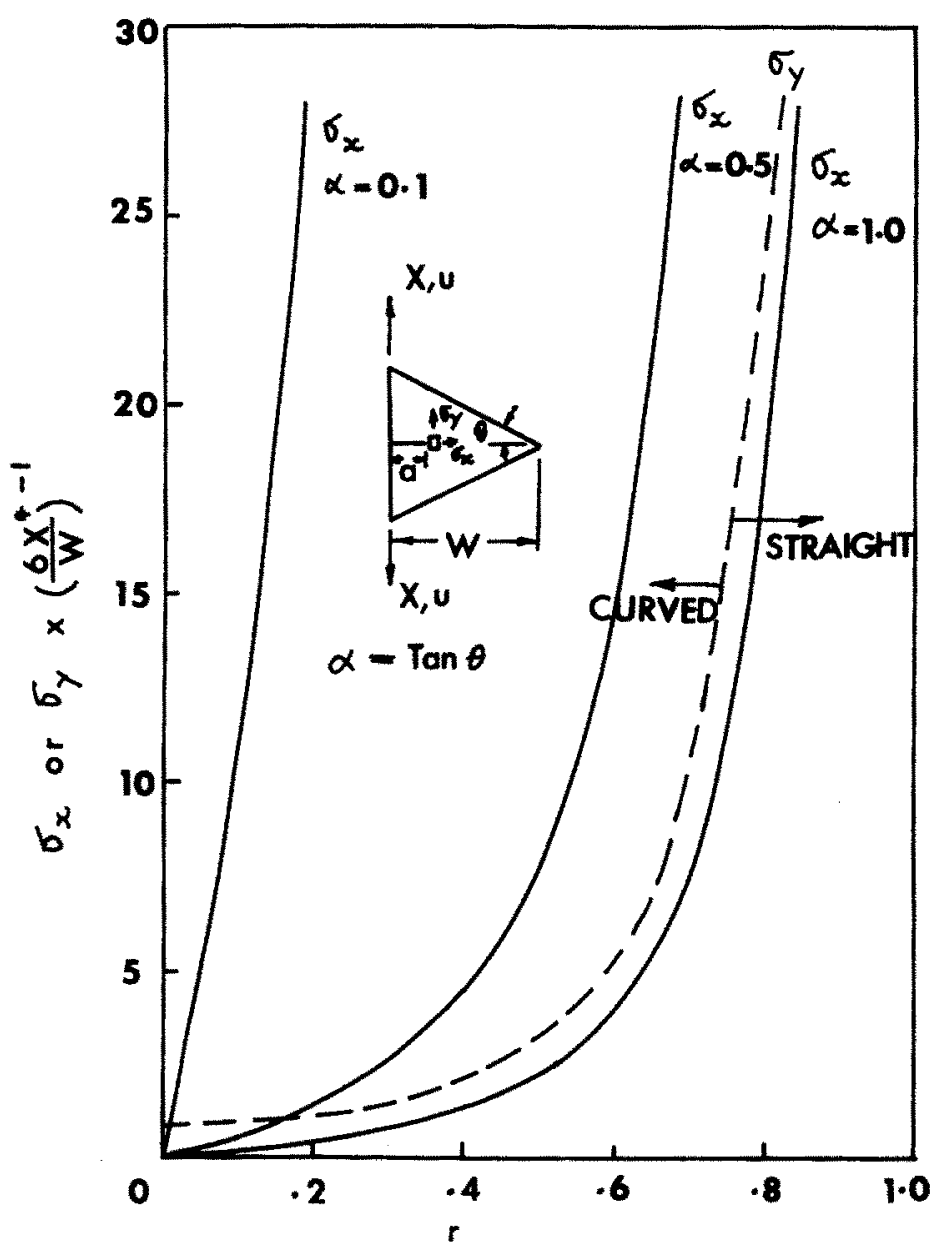

Figure $11 \mathrm{~b}$. A plot of non-dimensional stresses along and normal to the crack line for the modified DCB testpiece. 


$$
X \cdot \dot{u}=[2 R+(u \mathrm{~d} X / \mathrm{d} A)] \dot{A} .
$$

So the ratio of crack velocity to crosshead speed in a plate of thickness $t$ becomes

$$
\frac{\dot{a}}{\dot{u}}=\frac{1}{t}\left[\frac{X}{2 R+(u \mathrm{~d} X / \mathrm{d} A)}\right] .
$$

Knowledge of testpiece compliances (such as Eqns. $(5,6,14))$ or expressions for the stress intensity factor (such as Eqns. $(2,3)$ ) allows $(\dot{a} / \dot{u})$ to be calculated. In both the case of a tapered DCB specimen loaded at its apex and also the case of a tapered DCB specimen loaded at the thick base, it will be found that

$$
(\dot{a} / \dot{u})=(E W / R)^{\frac{1}{2}}\{\text { function of } \alpha, b, r\}
$$

where the non-dimensional function is different for the two cases [11].

In general, the crack velocity in specimens loaded at the thick base decreased during crack propagation, and noticeable differences in $R$ are measured by Gurney's sector area method [6] in rate-sensitive materials. Valuable $R(\dot{a})$ information for a given material under a constant environment and stress situation can be derived by varying the crosshead speed and monitoring crack propagation. The crack slows down in tapered DCB specimens loaded at the thick base, because physically, there is less strain energy available as the crack propagates to the apex of the triangular lamina. Indeed, an "arrow-head" shape specimen is suggested for straight. slow cracks when the $\sigma_{x}$ and $\sigma_{y}$ expressions for parallel DCB specimens are equated to give a shape for the external boundary of the testpiece [11].

On the other hand, the crack velocity in tapered DCB specimens loaded at the apex tends to remain roughly constant throughout cracking when there is no crack turning. Figure 10 gives a comparison of experimental values.

The presence of grooves results in an increase of crack velocity, other things being equal. The velocity ratio $(\dot{a} / \dot{u})$ in $(21)$, is increased by the square root of the groove ratio $\left(t / t^{*}\right)$.

It may be noted that the $(\dot{a} / \dot{u})$ ratio depends on $W^{\frac{t}{3}}$, so that cracks run more quickly in geometrically similar large structures for same $E, R$. This is a manifestation of the scalling laws in cracking $[6,11]$.

\section{Conclusions}

1. When compared with beams of uniform depth, tapered specimens loaded at the apex have been shown experimentally to be less stable in stiff systems. The degree of instability increases with the angle of the slope.

2. A modified test configuration with loadings applied at the back face instead of close to the apex results in better crack stability and control of the crack path. The crack will spread straight for all values of starting crack length when the semiangle is at least $45^{\circ}$; this angle may be reduced by grooving, but at the expense of increased crack velocity. Hence, backface loading may be chosen as an optimum alternative means for the determination of valid fracture toughness of materials, especially when good stability of cracking is desired, such as in environmental testing.

3. The simple criterion, $\sigma_{y} / \sigma_{x}>1.0$ coupled with elementary beam theory for the determination of a straight propagating crack along the midplane of the specimen, is shown to be adequate in the present analyses. 


\section{Acknowledgement}

One of us (YWM) wishes to thank Professor Charles Gurney for helpful discussions when portions of this work were performed at the University of Hong Kong, Department of Mechanical Engineering.

\section{REFERENCES}

[1] J. J. Gilman, J. Appl. Phys., 31 (1960) 2208-2218.

[2] J. J. Benbow and F. C. Roesler, Proc. Phy. Soc., London B70 (1957) 201-211.

[3] J. J. Benbow, Proc. Phys. Soc., London B78 (1961) 970-978.

[4] P. P. Gillis and J. J. Gilman, J. Appl. Phys., 35 (1964) 647-658.

[5] J. P. Berry, J. Appl. Phys., 34 (1963) 62-68.

[6] C. Gurney and J. Hunt, Proc. Roy. Soc., London A299 (1967) 508-524.

[7] C. Gurney and K. M. Ngan, Proc. Roy. Soc., London A325 (1971) 207-222.

[8] C. Gurney and Y. W. Mai, Engr. Fract. Mech., 4 (1972) 853-863.

[9] S. Mostovoy, P. B. Crosley and E. J. Ripling, J. Materials, 2 , 3 (1967) 661.

[10] J. E. Srawley and B. Gross, Materials Research and Standards, 7, 4 (1967) 155-162.

[11] A. G. Atkins and R. M. Caddell, presented at the Winter Annual Meeting of ASME, New York (1972).

[12] D. P. Clausing, Int. J. Fracture, 5 (1969) 211-227.

[13] A. G. Atkins and R. M. Caddell, Engr. Fract. Mech., 6 (1974) 209.

[14] G. C. Sih, Engr. Fract. Mech., 5 (1973) 365-377.

[15] V. V. Dudukalenko and N. B. Ramolis, Izv. AN SSSR. Mekhaniko Tverdogo Tela, 8, 2(1973) 129-136.

[16] J. G. Williams and P. D. Ewing, Int. J. Fract. Mech., 8 (1972) 441-446.

[17] B. W. Cherry and N. L. Harrison, Fibre Science and Technology, 2 (1970) 299-301.

[18] K. Palaniswamy and W. G. Knauss, Report SM 748, Graduate Aeronautical Laboratory, CIT (1974).

[19] W. G. Knauss, (private communication) (1974).

[20] B. Cotterell, Int. J. Fract. Mech., 6 (1970) 189-192.

\section{RÉSUMÉ}

On montre que les éprouvettes doubles Cantilever conventionelles à bords convergents et chargées à leur extrémité présentent une stabilité moindre que les éprouvettes à bords parallèles, lors de la fissuration sous des conditions d'essai rigides. On suggère un essai moditié, où les charges sont appliquées du côté le plus épais au lieu du voisinage de la pointe de l'éprouvette.

Les expériences confirment la théorie selon laquelle cette configuration accroit la stabilité de la fissuration, et contrôle davantage le parcours de la fissure, tout en permettant de couvrir, dans un même essai, une gamme plus large de vitesses de fissuration. 